\title{
THE IMPACT OF ORAL SUCROSE ON APNEA AND BRADYCARDIA IN PRETERM INFANTS:
} A CROSSOVER RANDOMISED TRIAL

\author{
T. Karen ${ }^{1,2}$, S. Vatlach ${ }^{1}$, A. Poets ${ }^{1}$, C. Maas ${ }^{1}$, C. Poets ${ }^{1}$, D. Bassler ${ }^{1,3}$ \\ ${ }^{1}$ Neonatology, University Children's Hospital Tuebingen, Tuebingen, ${ }^{2}$ Neonatology, University Children's \\ Hospital Essen, Essen, ${ }^{3}$ Center for Pediatric Clinical Studies, University Children's Hospital Tuebingen, \\ Tuebingen, Germany
}

Background and aims: Apnea of prematurity is a common problem in preterm infants. Pain and stress promote its occurence. Oral sucrose has been shown to reduce pain in neonates. We aimed to investigate the effect of oral sucrose on the prevention of apnea and bradycardia.

Methods: In this prospective, randomised controlled trial, 20 preterm infants with recurrent idiopathic apnea of prematurity treated with coffein and nasal CPAP were randomly assigned into 2 groups: Group 1 received $0.2 \mathrm{ml}$ sucrose in the first night before every handling or clinically indicated diagnostic intervention and 0.2 $\mathrm{ml}$ sterile water in the second night, Group 2 in inverse order. Primary outcome were the occurence of desaturation events $<80 \%$ (Index of desaturation 80; DI 80) and of bradycardia $<80 /$ min (Index of bradycardia 80, BI 80) per hour of monitor recording. Secondary outcome parameter was the apnea score (Poets C., Acta Paediatr. 2010) specified by nurses during the two nights (=9 hours per night).

Results: Neither the difference between sterile water and sucrose in the numbers of desaturations $(\mathrm{p}=0.8)$ and bradycardia $(\mathrm{p}=0.18)$ or the apnea score $(\mathrm{p}=0.8)$ was statistically significant.

Conclusion: The administration of oral sucrose for the prevention of stress and pain did not reduce the incidence of apnea of prematurity. 